\title{
Temas centrales de la historia norteamericana*
}

\section{Oscar Handlin}

Los norteamericanos siempre han estado conscientes de la necesidad de registrar su propia historia. Tal vez porque su pasado como pueblo era demasiado breve y porque estaban muy dispuestos a mirar hacia el futuro, se entregaron a la investigación periódica sobre el significado de su propia experiencia. Nunca se vieron obligados a romper con la influencia de Europa, pero las circunstancias de su cultura dieron un giro característico a los trabajos de sus historiadores. A pesar de cambios radicales en los modos de interpretación y en los métodos usados durante los tres siglos pasados, existen también continuidades fundamentales de gran importancia en el tema. El eclecticismo dominante de los historiadores norteamericanos contemporáneos no opaca la influencia constante que una larga tradición ejerce sobre ellos.

En retrospectiva, esta tradición parece haber pasado por cuatro fases diferentes antes de manifestarse en su forma actual. Durante la mayor parte del siglo XVII fue moldeada por las opiniones de los europeos para explicar y justificar su migración. En el siglo XVIII comenzó a sentir el peso de la inquietud por la búsqueda de lo nacional norteamericano. Después de 1820 , más o menos; fue sensible a los impulsos románticos de la época. $Y$ hacia fines del siglo XIX respondió al reto del saber que la transformó en una ciencia. Cada giro de la tradición dejó una huella permanente sobre los métodos y supuestos de los historiadores norteamericanos. ${ }^{1}$

Los primeros norteamericanos pensaron que la historia era el registro de su propia experiencia y para compilar dicho registro, le dedicaron extrema atención. Fue asunto de primera importancia que los propósitos de la colonización se comprendieran y que sus triunfos fueran conocidos. Los establecimientos primarios en los que vivian sólo podrían prosperar con la ayuda de la llegada inmediata de hombres y capital de Europa; y, únicamente la convicción de que las plantaciones del Nuevo Mundo estaban firmemente establecidas, podía alentar las inversiones e inmigrantes necesarios del Viejo Mundo.

Hubo, por lo tanto, un tono de promoción en todos los relatos del siglo XVII -aquellos de John Smith y William Wood son casos

* Anglia. Anuario de Estudios Angloamericanos, Vol. I, México, UNAM, Facultad de Filosofía y Letras, 1968. Trad. Mario A. Contreras.

1 En general, véase Harvard Guide to American History, Cambridge, Mass., 1954; W.T.Hutch inson, Marcus W. Jernegan Essays in American Historiography, Chicago, 1937; Michael Kraus, The Writing of American History, Norman Oklahoma, 1953; Oscar Handlin, "Les Américaines devant leur passé”, Diogène, VI (Avril 1954), 27. 
típicos- como si se hubieran escrito para un lector europeo, un tanto escéptico. En ocasiones, el empeño para persuadir hacía pintoresca la narración y algunas veces, por ejemplo, producía versiones de exactitud dudosa. A menudo estos trabajos fueron producidos en forma de cuentos picarescos de viajes, que Hakluyt y otros hicieron populares en este tiempo: formas más conducentes a gustos imaginarios que a la interpretación literal de los acontecimientos.

Entre los puritanos de la Nueva Inglaterra una necesidad más para convencer al mundo transatlántico incrementó la urgencia de sus escritos. También se preocuparon por aumentar fuerza a las endebles colonias que, por su parte, no eran pura y simplemente empresas comerciales. Habían partido de Inglaterra animados también de otro motivo: el deseo de establecer en los lugares despoblados de América una Nueva Canaán, un Estado guiado por la Ley Divina. El éxito de su experimento, creían, era de primordial importancia para toda la humanidad, ya que su sociedad iba a ser una ciudad sobre una colina, un modelo visible que demostraría a los hombres de todo el mundo el justo camino para la redención. Describir las operaciones de dicho modelo, de tal manera que todas las naciones de la tierra pudieran comprenderlo, se consideró el momento culminante. Ese fue el propósito de tales historias como las de Edward Johnson, Nathaniel Morton, William Hubbard, y Mather, escritas en esta época. ${ }^{2}$

La convicción de que América estaba destinada a una misión peculiar nunca desapareció del todo de los trabajos de los historiadores en los Estados Unidos. En el siglo XVIII la idea de tal misión fue secularizada y se transformó en la difusión del republicanismo y la democracia en todo el mundo. Ese espíritu se respiró aun en la obra de Bancroft y sus contemporáneos y se convirtió en un elemento más de las ideas' de una generación posterior, que consideró a los Estados Unidos a la vanguardia de un proceso general de evolución a través del cual toda la gente se movía. La influencia de tal convicción todavía se encuentra entre los historiadores que, conscientes del reto del totalitarismo, buscan en el pasado americano las claves del sentido y los medios de defensa de la libertad.

Durante el siglo XVII, el concepto que los historiadores tenían de su misión había sido sencillo y coherente, al servicio del propósito que perseguian. Cada evento era una manifestación directa de la voluntad de Dios; pero esos eventos dignos de registrarse, eran sólo para revelar algún designio particular de su parte. Los incidentes regulares con que contaron en su vida, por consiguiente, fueron de menor importancia que los maravillosos o excepcionales que podrían ser reconocidos como evidencia del propósito divino. En el caso de los puritanos, escogidos para desempeñar un papel predestinado, su historia fue el registro de la Providencia milagrosa que probaba su misión. Aun los incidentes penosos, como la serie de las amargas guerras contra los indios en el último cuarto del

2 Edward Johnson, Wonder Working Providence, ed. J.J. Jameson, 1910; Thomas Morton, New England Canaan, Amsterdam, 1637 (ed. C.F. Adams, 1883); Cotton Mather, Magnalia Christi, 1702 (reimpreso en 1853); K.B. Murdok, Literature and Theology in Colonial New England, Cambridge, Mass., 1949. 
siglo, fueron explicados como resultantes de la misma causa particular. El gusto o disgusto de Dios, explicaba todo. ${ }^{3}$

Sin embargo, a medida que terminaba el siglo XVII, y en el momento en que las primeras generaciones desaparecian, el fervor de la fe puritana empezó a decaer. En el siglo Xvili, en cualquier parte de las colonias norteamericanas, la diseminación de las influencias racionalistas exting uió la propensión a creer en una Providencia que interfería directamente en los asuntos de los hombres. La influencia de la ilustración europea no se demoró en cruzar el Atlántico; y las influencias autóctonas - diversidad de religiones y debilidad de la iglesia establecida - alentaron a los norteamericanos cada vez más, a no aceptar opiniones de tono deísta. A tal grado, que Dios se convirtió en el lejano relojero, su mano ya no podía percibirse en las operaciones del reloj, excepto hasta donde se establecían los principios generales que gobernaron su mecanismo.

La Providencia, por lo tanto, desempeñó un papel cada vez menos prominente en la historia del siglo XVIII. En cambio, los cronistas de la época se sintieron forzados, con mayor frecuencia, a proporcionar explicaciones naturales de los hechos. Sin todavía estar más que vagamente enterados de las concepciones de continuidad e historicidad que animaron a los historiadores y filósofos europeos, los norteamericanos fueron llevados, sin lugar a dudas, a buscar las causas de los acontecimientos no ya en la mano de Dios, sino en sus propios antecedentes. En la búsqueda por antecedentes, los escritores se vieron ahora compelidos a dedicarle meticulosa atención al pasado. La historia no sería para ellos, como lo había sido en el siglo XVII, fundamentalmente un registro de sus propias experiencias.

Dos consecuencias se produjeron. La evidencia documental adquirió nueva importancia. John Callender, el historiador de Rhode Island, hizo una defensa notable de la colección y preservación de dichos materiales; y fue la índole de sus fuentes la que constriñó a la mayoría de estos autores (con la excepción de William Douglass) a producir sus trabajos en forma de historias individuales de las colonias. ${ }^{4}$

Además, los escritores de este periodo consagraron buen acopio de energía al examen sobre los orígenes de sus temas. History of New England de Thomas Prince (1736) fue, así, ampliamente dedicada a los primeros años de la colonización, y dichas asignaciones de espacio llegaron a ser características en los escritos de la segunda mitad del siglo.

La búsqueda de los orígenes condujo directamente a especulaciones sobre el carácter de los norteamericanos, que eran los sujetos de estos trabajos. Mención frecuente y mucho más favorable fue consagrada a los indios, tanto en libros dedicados por completo a ellos, como History of the Five Indian Nations de Cadwallader Colden, ya en libros más generales, como History of Virginia de Beverley. En estas disertaciones estuvo implícita la posibilidad de que las costumbres y formas sociales podrían ofrecer un indicio de lo que

3 Los trabajos sobre las guerras de indios están registrados en Harvard Guide to American History, p. 278.

1 John Callender, Historical Discourse on Rhode Island, 1793 (reimpreso por la Rhode Island Hist. Soc., Collections, IV, 1838). 
los norteamericanos del futuro llegarían a ser, después de haber estado, por generaciones, sujetos al medio ambiente del Nuevo Mundo. ${ }^{5}$

Cada vez en mayor medida estuvieron dispuestos a creer que ese medio ambiente conformaba una nueva clase de gente. Siempre los historiadores habian intentado dar descripciones gráficas del salvajismo del lugar y de sus penalidades; pero las actitudes de este periodo fueron diferentes de aquellas del siglo XVII. Anteriormente la frontera había sido un enemigo que se rendía a las avanzadas europeas; ahora, para bien o para mal, parecía transformar al hombre que vivía dentro de su influencia. La obra History of the Dividing Line de William Byrd II trató explícitamente del proceso y otros lo retocaron de una manera informal, mas no por ello menos importante. ${ }^{6}$

La influencia de la frontera como fuente de la singularidad de las instituciones norteamericanas, se convirtió en tema favorito entre los historiadores de los siglos XIX y XX. Brotó en los escritos de Francis Parkman y H. H. Bancroft, recibió expresión sistemática en las manos de Frederick Jackson Turner y posteriormente, fue reiterado en forma extrema, por W. $\mathbf{P}$. Webb. Por generaciones, la frontera adquirió un complejo de connotaciones sentimentales como la matriz dentro de la cual su carácter distintivo como pueblo había sido moldeado. ${ }^{7}$

Mientras tanto, los sucesos del cuarto de siglo revolucionario después de 1775 , habían proporcionado un nuevo interés para la historia norteamericana. Los hombres de la nueva nación confiaban que el registro del pasado podría no sólo vindicar su oposición a la autoridad real, sino que también justificaría la independencia como acto legítimo de un pueblo, ya separado de Inglaterra en todo, menos en gobierno. Pero ni siquiera las finalidades ni los métodos de la historia escrita en los años siguientes, fueron nuevos. Las obras de Jeremy Belknap, Mercy Warren y sus contemporáneos, no fueron muy diferentes en espíritu o técnica de aquellos escritores prerrevolucionarios como Thomas Hutchinson. ${ }^{8}$

Un rompimiento importante en los patrones de la historiografía norteamericana ocurrió después de 1820. Después de las largas interrupciones que precedieron a la Revolución y a las guerras de Napoleón, los ciudadanos de los Estados Unidos empezaron a restablecer contactos culturales con Europa. Empezaron a entrar las corrientes del pensamiento romántico que estaban de moda en Francia, Inglaterra y Alemania, y nuevas concepciones transformaron su opinión de la historia.

Sólo algunos escritores norteamericanos estuvieron seriamente influidos por las filosofías de la historia que entonces ocupaban a

3 Cadwallader Colden, History of the Five Indian Nations, 1747 (reimpreso en 1922); Robert Beverly, History of Virginia, 1722 (ed. L.B. Wright, 1947).

6 William Byrd II, Histories of Dividing Line, ed. W.K. Boyd, 1929.

7 Francis Parkman. Oregon Trail, Nueva York, 1849, France and England in North America, Boston, 1865-92; y Conspiracy of Pontiac, Boston, 1851; H.H. Bancroft, History of the Pacific States of North America, San Francisco, 1882-90; F.J. Turner, Frontier in America History, Nueva York, 1850; W.P. Webb, Great Plains, Boston, 1931.

Jeremy Belknap, History of New Hampshire, Boston, 1791-92; Mercy Warren, History of the American Revolution, Boston, 1805; W.T. Hutchinson, History of Massachusetts Bay, nueva ed., Cambridge, Mass., 1936. 
tantos de sus contemporáneos al otro lado del Atlántico. Más importante fue la aceptación de un modelo de posturas románticas $\mathrm{e}$ ideas, generalmente transmitido en forma literaria: el héroe como protagonista luchando contra inmensas fuerzas hostiles, el choque de ideas conflictivas a través del pasado, la influencia poderosa de la naturaleza y el poder de un destino indefinido, inherente en el carácter de hombres y naciones. En cierto sentido, Scott y Byron suministraron los conceptos de la generación de historiadores norteamericanos posterior a 1820, más que Hegel y aun Macaulay.

Estas influencias románticas enfatizaron las tendencias ya visibles en semejantes obras como la vida de Washington, de Marshall. La historia iba a ser escrita en gran escala y con sentido épico. Iba a hablar de los esfuerzos de grandes personajes - nobles o malvados- para hacerlos valer como únicos en su especie. Y también iba a exponer el choque de ideales opuestos o discordantes. Estas finalidades iban a ser llevadas a cabo, como en otras formas literarias, poniendo especial énfasis en la narración, pues, implícitos en esta posición estaban los supuestos de que la historia cronológica propiamente dicha, suministraría su propia organización y facilitaría a las partes componentes del todo caer dentro de sus esferas propias. ${ }^{9}$

Por unos sesenta años la narración fue el estilo prevaleciente de los escritos históricos en los Estados Unidos. Los volúmenes de Francis Parkman y George Bancroft alcanzaron un alto grado de popularidad y desparramaron por la nación un conocimiento difuso del propio pasado. También condujo a algunos norteamericanos a empezar a adentrarse en la historia de otros países. En la búsqueda de material atractivo, Prescott acudió a España y Motley a los Países Bajos, y sus libros encontraron una respuesta muy favorable del público. ${ }^{10}$

Si bien estos autores se consideraron a sí mismos como narradores de historietas, estuvieron, no obstante, completamente conscientes de que sus relatos diferían de aquellos de los novelistas. Se comprometieron a la investigación irremisible de la información verdadera sobre la que ellos pensaban, debían descansar sus narraciones. Parkman y Bancroft fueron investigadores prodigiosos y nunca permitieron conscientemente que la habilidad con la pluma disminuyera su celo por la documentación. A decir verdad, en estos mismos años, Jared Sparks y George Ticknor, J. R. Brodhead y Poter Force, y otros; empezaron a formar bibliotecas, colecciones de manuscritos y series de publicaciones que suministrarían a los futuros historiadores soberbias facilidades de investigación.

Cada vez más, la necesidad de una documentación crítica y el objetivo de una narración de fácil lectura empezaron a interferirse. Los datos aumentaron en una abundancia embarazosa y dificultaron aún más mantener los supuestos de que la narración hablaría por sí misma, sin algún principio definido de selección o sin desviaciones en la organización de la cronología inmediata. Así, $\mathrm{Na}$ rrative and Critical History de Justin Winsor, permitió al aparato crítico enterrar al texto narrativo. Henry Adams, quizá el más sensible historiador de la forma narrativa, enfrentó el mismo problema. En su History of the United States during the Administrations of

9 John Marshall, Life of George Washington, 1804-7.

10 George Bancroft, History of the United States, Boston, 1834-74. 
Jefferson and Madison sus intentos para darle suficiente fuerza dieron por resultado una marcada disyunción entre los capítulos introductorios y finales de la obra, por un lado, y el cuerpo principal del texto, por el otro. Finalmente, en J. B. MacMaster, el empeño por colmar con una gran variedad de diversos datos un simple trabajo, lo condujo al sacrificio total de las cualidades narrativas. En las últimas décadas del siglo era patente la gran acumulación de hechos que tenían que ser abordados de manera más selectiva; eso sólo podría lograrse si el historiador los tomaba y les planteaba preguntas formuladas, cuya solución proveería a la obra de una base coherente de organización. ${ }^{11}$

La historia narrativa continuó escribiéndose con J. F. Rhodes, Edward Channing, E. P. Oberholtzer y últimamente con Allan Nevins, entre otros. El estilo predominante de la biografía histórica también continuó utilizando el supuesto de que la historia de la vida de un personaje era, en sí misma, un esquema útil de organización. Pero después de 1880 el énfasis de la historiografía norteamericana se desvió a problemas manejados de diferentes maneras. ${ }^{12}$

A pesar de todo, los historiadores norteamericanos permanecieron sensibles a los deberes heredados de los escritores narradores del siglo XIX. Parkman y Bancroft se constituyeron en un recuerdo continuo de que el historiador no escribía para un pequeño grupo minoritario, sino para todo el público. Lógicamente, los historiadores norteamericanos fueron hostiles a la difusión de la jerigonza o de la terminología esotérica y al estilo abstruso. Si bien otros factores dificultaron, después de 1900, el atraer un vasto auditorio, aún sentían la necesidad de escribir para un grupo de lectores tan numeroso como fuera posible. El deber hacia la educación popular y el progreso continuaron siendo la herencia de la tradición narrativa.

En la década de los ochenta el cambio de énfasis en la tradición había sido notable. Una revisión consciente de los objetivos y métodos acompañaron al cambio. Entre aquellos involucrados, el nuevo desarrollo fue a menudo descrito como la creación de la ciencia de la historia, que nunca más sería el campo de los literatos sino de expertos profesionales, entrenados en las técnicas precisas para la indagación objetiva de la verdad. Aunque ahora y después hubo una disposición para exagerar las diferencias entre los historiadores y sus predecesores, la nueva escuela partía de tres puntos cruciales sacados de las suposiciones de los escritores de la historia narrativa.

Los historiadores narradores se habian ocupado de las fuentes originales, pero para ellos la precisión de detalles era de menores consecuencias que la gran verdad que deseaban transmitir. No vieron ningún daño en la alteración de los textos, con tal de alcanzar dicha gran verdad. Para los historiadores científicos eso era incomprensible. Por supuesto, estos eruditos plasmaron en sus trabajos

11 Justin Winsor (comp.), Narrative and Critical History of America, Boston, 1884-89; Henry Adams, History of the United States, Nueva York, 1889-91; J.B MacMaster, History of the People of the United States, Nueva York, 1883-1913.

12 J.F. Rhodes, History of the United States from 1850, Nueva York, 1893-1906; Edward Channing, History of the United States, Nueva York, 1905-25; E. P. Oberholtzer, History of the United States since the Civil War, Nueva York, 1917-37; Allan Nevins, Ordeal of Union, Nueva York, 1947. 
los prejuicios y predisposiciones de su tiempo y circunstancia. Debido a su preocupación por la objetividad, apenas se imaginaron que podrían nulificarlos. Pero se habían dedicado a la objetividad en un sentido más significativo; aceptaron el hecho como absolutamente indiscutible y en su investigación (como se vislumbró en sus ensayos ocasionales) elevaron la precisión al puesto de la más alta virtud.

Eso explicaba sus ansias por profesionalizar ias técnicas, por reducir a métodos precisos los recursos para verificar los datos. Los seminarios, ya introducidos en las universidades de Michigan, Harvard y Johns Hopkins, imitando a los de Alemania, habían de ser talleres en los cuales los jóvenes aspirantes podrían adquirir la habilidad de la ciencia; el doctorado iba a ser la contraseña de admisión en la cofradía; y la Asociación de Historia Norteamericana (American Historical Association), fundada en 1884, a través de sus juntas y publicaciones fomentaría el mantenimiento de niveles apropiados. Una multitud de eruditos tenaces se propuso la tarea de crear el arsenal de bibliografías y guías y manuales, de los que sus sucesores podrían extraer las armas que usarían en la lucha para hacer más precisas las aproximaciones a la verdad.

Los nuevos investigadores raras veces pensaron que el producto de su trabajo sería un libro extenso y general, una narración. Mejor dicho, concibieron que el conveniente escenario para sus resultados fuera la monografía, trabajo análogo al reporte de una investiga- ción en las ciencias físicas. La monografía aisló un problema histórico particular sacado a relucir para que todos los acontecimientos relevantes, giraran alrededor de él -acumulados y manejados con las técnicas más refinadas- y rindieran una conclusión evidente apoyada con pruebas. Desde 1880 los avances más importantes en el conocimiento histórico se han producido dentro de la investigación de tipo monográfico.

Para algunos eruditos la selección de un tema fue casi casual. Considerando sus trabajos como ejercicios de virtuosismo, casi llegaron a expresar que todos los problemas eran igualmente dignos de examen y, a la manera de los científicos "puros", se rehusaron a considerar como consecuentes las aplicaciones prácticas o el sentido externo de sus estudios. Un gran caudal de energia fue así consumido en examinar el tema Colón y la validez de las reclamaciones de los primeros exploradores. ${ }^{13}$

Pero no fue ésta la opinión prevaleciente. Por lo común se arguyó que, aunque la monografía se ocupaba de un pequeño segmento del pasado, su significado inherente a la luz de sus conclusiones, iluminaba los problemas generales. A aquellos problemas les fue dado un sistema en las ciencias sociales, en referencia al cual los datos proporcionados por la historia adquirieron importancia. No fue una casualidad que la organización de las universidades norteamericanas en estas décadas no estableciera, en general, la historia separadamente, sino asociada en departamentos con una o más de las ciencias sociales.

La historia se convirtió así en ayudante de la ciencia política o económica, pero su papel, no obstante, era vital. Aquellas disciplinas estaban cambiando, por el momento, su orientación primaria

13 Para esta bibliografía véase Harvard Guide to American History, p. 251-255. 
que había sido predominantemente teorética, abstracta y analítica. Por la influencia de Spencer, de los otros darwinistas y, en cierta medida de Comte, los filósofos moralistas en proceso de convertirse en científicos sociales, dejaron de dedicarse a la búsqueda de principios absolutos y consideraron su propio problema como el indicio natural del desarrollo. Estos nuevos intereses incrementaron la importancia de la perspectiva del tiempo y le otorgaron a los datos históricos un significado científico nuevo.

Al comienzo del siglo $\mathrm{xx}$, la mayoría de los intelectuales norteamericanos llegaron a la conclusión de que la vida de la sociedad estaba organizada en instituciones que habian evolucionado a través del tiempo; la función del historiador fue descubrir los origenes de dichas instituciones $y$, de este modo, aclarar los gérmenes de donde se reprodujeron. La forma del lenguaje en que estos conceptos se expresaron - germen, evolución, desarrollo- revelaban que cada institución era considerada, en gran parte, con contenido propio y autorreproductora. Estaba afectada ligeramente por el medio ambiente circundante y podía ser entendida en términos de sus propias e inherentes leyes. de desarrollo.

Los intereses de los historiadores institucionales fueron en gran medida políticos, y las contribuciones en ese campo de H.L. Osgood, G.L. Beer y C.M. Andrews tienen importancia todavía. En parte, dicho énfasis fue internacional; los estudiantes en el seminario de H.B. Adams en la Johns Hopkins, frecuentemente recordaban el precepto de Freeman: "La historia es la política del pasado." Pero la concentración del interés en el desarrollo constitucional y gubernamental influyó también en la ya existente preocupación popular norteamericana por la política y la creencia general, entonces común, de que los logros más importantes en los Estados Unidos estaban relacionados con la democracia política. ${ }^{14}$

Pero el tratamiento institucional fue aplicado con igual firmeza, y también con mucho éxito, en otros campos. W.J. Ashley y E.F. Gay, ambos producto de la preparación europea, fundaron una vigorosa escuela de historia económica, que contribuyó notablemente en esa materia en el primer cuarto del nuevo siglo. $Y$ los intereses de Albion, Small y algunos otros sociólogos, los llevaron a fomentar la investigación histórica en ese campo. De hecho, casi se puede afirmar que escritores como M.C. Tyler llevaron a cabo el mismo tratamiento en la literatura. ${ }^{15}$

La preocupación por el desarrollo institucional hizo que la atención de los eruditos norteamericanos volviera a cruzar el Atlántico. En la búsqueda de los orígenes fue sin duda crucial ver el fondo europeo de las instituciones del Nuevo Mundo; podía muy bien ser que el gerrnen de la democracia norteamericana estuviera, después de todo, localizada en los bosques de Alemania. Muchos

14 H.L. Osgood, American Colonies in the Seventeenth Century, Nueva York, 1904-7; y American Colonies in the Eighteenth Century, Nueva York, 1924-25; G.L. Beer, Origins of British Colonial System, Nueva York, 1908; Old Colonial System, Nueva York, 1912; y British Colonial Policy, Nueva York, 1907; C.M. Andrews, Colonial Period of American History, New Haven, 1934-38.

15 Por ejemplo las publicaciones en Carnegie Institution's Economic History Series; en Harvard Economic Studies; y en Columbia University Studies in History, Economics and Public Law; M.C. Tyler, History of American Literature, 1878 (reimpreso en 1949). 
estudiantes como C.H. Haskins y C.L. Becker empezaron su carrera con el estudio sobre problemas especiales en la historia de los Estados Unidos y luego se ocuparon de la consideración de los antecedentes europeos. La investigación y la enseñanza en una escala más amplia fueron, desde luego, también alentados por el creciente compromiso de la nación en los asuntos mundiales después de 1898 y por el constante aumento de material disponible en las bibliotecas y universidades norteamericanas. Paradójicamente, sin embargo, el mismo aumento de estos materiales y el incremento en la especialización, producto de los niveles ascendentes de la competencia profesional, hicieron cada vez más difícil después de la Primera Guerra Mundial, el efectuar dichas transferencias de interés tal y como Haskins y Becker las manejaron. Se volvió cada vez más peligroso aventurarse en un campo extraño y cada vez más necesario para cada casero, limpiar su propia casa.

Esta especialización fue un reflejo de la contribución más duradera de la escuela científica a la tradición de la historiografía norteamericana. No estuvo lejos el momento en que la insatisfacción pudo llevar el tratamiento institucional a su total abandono o cuando menos a modificaciones radicales. Pero el profesionalismo de la época, consciente de sí mismo, persistió, y con él la insistencia sobre la precisión y exactitud de los métodos, que han quedado como características esenciales de la historiografía de los Estados Unidos, hasta nuestros días. La insistencia sobre la calidad científica de la historia, a veces se sitúa incongruentemente entre las nociones del excepcionalismo norteamericano, la pretensión de que el Nuevo Mundo creó un pueblo nuevo y el deber de fortalecer al público, que los historiadores han heredado de otros elementos de su tradición. Pero tales inconsistencias, si lo son, no parecen imponerse violentamente aun en los más susceptibles escritores del presente. Una aproximación que es esencialmente pragmática y ecléctica, les permite aceptar el peso de los diversos elementos que existen en su tradición sin titubear en su propia tarea de reinterpretar el pasado.

Las tendencias dominantes en la confección de la historia norteamericana de hoy son los resultados del abandono de los patrones impuestos por los institucionalistas. La insatisfacción con la historia institucional, proveniente de dos diferentes fuentes, rápidamente convenció a la erudición norteamericana. Los primeros indicios del rompimiento aparecieron tempranamente, antes de empezar el siglo. Para 1930 se había completado.

Frederick Jackson Turner apenas fue consciente del efecto, a largo plazo, que sus palabras tendrían cuando leyó su famoso escrito sobre la importancia de la frontera en la historia norteamericana, en 1893. Entonces, y más adelante, de hecho se habló de la frontera como si fuera una institución en sí misma y algunos de sus discípulos aceptaron la "interpretación de la frontera" dogmáticamente, y de esa manera mal interpretaron el significado de sus ideas, en su más amplio contenido.

La frontera y el oeste, como conceptos, ya para 1900 eran familiares a través del empeño de Lyman Draper, H.H. Bancroft, R.G. Thwaites y Theodore Roosevelt. Turner no hizo más que extender dichas ideas primarias. A través de su carrera como intelectual y maestro, se interesó menos en promover cualquier interpretación 
particular, que en lograr una opinión de los acontecimientos en su contexto íntegro. El alegó, en esencia, que tratar las instituciones políticas, económicas o religiosas, como si su desarrollo fuera completamente independiente y original, era engañoso; éstas sólo podrían ser entendidas en términos de sus interrelaciones en cualquier tiempo y lugar. Los más sugerentes trabajos de Turner y sus estudiantes fueron dedicados precisamente al examen de tales relaciones, entre la geografía y la política, entre el sistema de producción y la religión, y otros por el estilo. Al grado que los historiadores de las décadas siguientes se convencieron de los argumentos y abandonaron los supuestos de los institucionalistas. ${ }^{16}$

La otra fuente de descontento con los institucionalistas, fue el vigoroso grupo de ponentes de la nueva historia. Superficialmente, su crítica a la vieja historia iba dirigida a la estrechez de su preocupación por la política. James Harvey Robinson, Charles A. Beard y Carl L. Becker, entre otros, hicieron un llamado para otorgarle un campo mayor a la historia, uno que diera lugar al desarrollo de ideas, del arte, de la religión y de los sistemas tanto políticos, como sociales. ${ }^{17}$

Estos críticos, a primera vista, no comprendieron tampoco la verdadera naturaleza de su crítica. No fue realmente el exceso de la preocupación por la política lo que les incomodaba, sino más bien, el hecho de que los historiadores institucionales aceptaran el fenómeno de la política con valor nominal, como si se explicara completamente por sí misma. Del mismo modo que Turner, aquellos que clamaban por una nueva historia, estuvieron buscando una técnica para demostrar las relaciones entre los acontecimientos sociales, culturales, económicos y políticos; y si al principio prefirieron descuidar la política como tema, fue por la convicción de que otros campos por tanto tiempo olvidados, necesitaban atención más inmediata.

La presión de estas fuentes erosionó rápidamente los supuestos de los historiadores institucionales, y eso afectó profundamente los escritos de las tres últimas décadas. La índole de esa influencia puede ser entendida fácilmente por medio de un breve estudio de los más importantes campos de investigación, sobre los cuales han consumido sus energías los historiadores norteamericanos.

La primera respuesta a la pérdida de las viejas normas de disciplina, fue un sentimiento de gran entusiasmo por los nuevos territorios recientemente abiertos a los aventureros. El regionalismo, la situación de clases y otros grupos sociales, las ideas, la religión, las costumbres y la moral, eran campos fértiles que permanecían vírgenes y sin cultivar, esperando a los pioneros que los explotarían. Uno sólo tenía que plantear la demanda, encontrar un tema nuevo, y los resultados vendrían por sí mismos.

Sin embargo, no pasó mucho tiempo para darse cuenta que el proceso no era tan sencillo. A su debido tiempo, los hechos porme-

16 Véase la nota 7; también R.G. Thwaites (ed.), Early Western Travels, Cleveland, 1904-7; y Jesuit Relation, Cleveland, 1896-1901; Theodore Roosevelt, Winning of the West, Nueva York, 1889-96. Sobre Turner, véanse las obras citadas, Harvard Guide to American History, p. 21.

17 J.H. Robinson, New History, Nueva York, 1912; C.A. Beard, Nature of the Social Sciences, Nueva York, 1912; C.M. Beçker, Everyman His Own Historian, Nueva York, 1935; H. E. Barnes, New History and Social Studies, Nueva York, 1926. 
norizados fueron aumentados extensamente en las nuevas áreas de investigación, así como en las viejas. Pero sólo en contadas ocasiones hicieron que se alterara la opinión existente del pasado o le dieron nueva forma al entendimiento de los hombres acerca de su historia.

A pesar de lo conveniente como tema, el regionalismo probó ser un foco útil de estudio sólo en el caso del sur. Allí las características sociales y culturales comunes y un continuo sentido de identidad regional, ofrecieron las bases para una investigación fructífera. Allí también, la guerra civil -más crítica como experiencia social, que en otras regiones - proveía a los estudiosos de un punto de partida alentador. Con William E. Dodd, el estudio de esa parte de la historia fue más allá del escenario de la apologética, aunque voces persistentes sobre el problema de la pasada guerra, todavía hoy pueden ser escuchadas. Estudiantes responsables, de aquí en adelante, se impusieron la tarea de entender a la sociedad sureña; las contribuciones de Woodward, Abernethy, Buck y Owsley han recorrido un largo camino para lograrlo. En resumen, la historia conjunta del sur, editada por W.H. Stephenson, es una obra mejor que la que podría enorgullecer a cualquier otra región del país. ${ }^{18}$

En contraste, el oeste - ya definido-, no ha prestado en sí, a muchos historiadores la oportunidad de contribuir originalmente. La obra Old Northwest de R.C. Buley, trajo a un mismo tiempo un interesante conjunto de datos sociales, aunque sin una estructura sintética adecuada, para mantenerlos juntos. Great Plains de W.P. Webb por el otro lado, fue muy sugestiva e ilustrativa, a pesar de la debilidad en los detalles. Aparte de unos cuantos trabajos la gran masa de investigaciones monográficas relativas a esta área, ha llenado huecos en nuestros conocimientos, pero no ha hecho más. Hay señales prometedoras de que un estudio más especializado de la ecología de la región podría otorgar nueva comprensión a su historia, pero éstas aún son promesas. Aparte de esto, los trabajos más útiles en este campo han sido producidos por escritores cuyos estudios sobre el oeste no se han concentrado en la región como tal, sino más bien sobre los problemas generales en los cuales la región está comprendida. ${ }^{19}$

Las otras partes de la nación han demostrado ser aún menos fértiles. Fuera de los estudios ocasionales sobre su historia comercial y fabril, la Nueva Inglaterra, desde el siglo XVII, ha estado demasiado olvidada; los estados del centro parecen no haber constituido nunca una región, o parte de una sección, de alguna manera, con sentido para los historiadores. Con sólo pocas excepciones, por lo tanto, la concepción de una región no ha probado ser un punto de partida útil. Por el otro lado, los historiadores que han aprendido a tomar en cuenta las consideraciones regionales, en relación con los problemas de la historia económica, o constitucional, o diplomática, a veces han descubierto en dicha idea un arma conveniente.

18 W.E. Dodd, Cotton Kingdom, New Haven, 1921; C.V. Woodward, Tom Watsun, Nueva York, 1988; P. H. Buck, Road to Reunion, Boston, 1937; F.L. Owsley, Plain Folk of Old South, 1949; W. J. Cash, Mind of the South, Nueva York, 1941; W.H. Stephenson y E.M. Coulter (eds.), History of the South, Baton Rouge, La., 1948-53.

19 R.C. Buley, Old Northwest, Indianapolis, 1950; también véase la nota 7. 
Los historiadores que se volvieron a la historia social también descubrieron que se les exigía algo más que encontrar temas no trillados. Una gran cantidad de información sobre los modos de vida populares, los hábitos de la gente, los patrones familiares y cosas por el estilo, ya se había deslizado en las historias narrativas e institucionales, particularmente en las historias locales. Pero los historiadores sociales confiaban en darles orden y sentido. The History of American Life Series, editada por A.M. Schlesinger y D.R. Fox, ordenó como útil guía y sumario cómodo la información existente sobre el tema. El estudio sobre ciudades coloniales de Carl Bridenbaugh y el estudio de la familia colonial de E.S. Morgan, dieron lugar a un nuevo campo. Pero pocos trabajos, desde entonces, han hecho algo más que agregar detalles a la descripción de American Life Series. ${ }^{20}$

Los nuevos historiadores habían esperado también que sus análisis de grupos sociales serían inmediatamente fructíferos. El concepto de clase era, por supuesto, difícil de aplicar en el contexto de las condiciones norteamericanas, y los historiadores de los Estados Unidos apenas estaban enterados de las frecuentes discusiones sofisticadas sobre dicho concepto, entre los teóricos europeos. Por lo común, los eruditos norteamericanos pensaban en términos de una división de intereses, descrita al comienzo del siglo por los populistas y sus herederos los progresistas, división que alineaba a los elementos agrarios contra los mercantiles y capitalistas en el orden social de la nación. El estudio de Charles A. Beard, sobre la democracia jeffersoniana, desarrolló este tema en relación con los primeros años de la república, y su Rise of American Civilization lo estableció en adelante como la llave para toda la historia norteamericana. Este último trabajo convirtió a los escritores que maduraron en 1930, en seguidores entusiastas de Beard. Sin embargo, pocos de ellos llevaron adelante la misma interpretación, tal vez porque Beard, careciendo de relaciones universitarias, no fue capaz de formar una escuela, o porque una vez que expuso el tema de una manera tan decisiva, no dejó nada que agregar al epígono sino notas, o quizá porque el tema en sí, no era susceptible de elaboración. Nadie ha llevado más adelante el esfuerzo para analizar y evaluar estos intereses en donde Beard los dejó. ${ }^{21}$

Hubo trabajos ocasionales que sí examinaron provechosamente el papel de los grupos particulares en un punto específico de crisis. A.M. Schlesinger investigó, con meticuloso detalle y con perspicacia, el desarrollo de las actitudes de los comerciantes coloniales hacia la Revolución Norteamericana. Pero aún dicho trabajo seminal no procuró examinar la constitución real del grupo en sí, y muy pocos intentos han ido más lejos desde entonces. Por esa razón, aunque las organizaciones, los resentimientos y los conflictos de agricultores y peones han sido muchas veces descritos, se ha pres-

20 Carl Bridenbaugh, Cities in the Wilderness, Nueva York, 1938; E.S. Morgan, Puritan Family, Boston, 1914.

${ }^{21}$ C.A. Beard (y M.R.), Rise of American Civilization, Nueva York, 1927-42; Economic Interpretation of the Constitution, Nueva York, 1913; y Economic Origins of Jeffersonian Democracy, Nueva York, 1915; W.E. Binkley, American Political Parties, Nueva York, 1943. 
tado poca atención a la composición y a las condiciones de vida y trabajo de los granjeros, de los artesanos o de los obreros. ${ }^{22}$

No cabe duda que era más simple, dadas las circunstancias norteamericanas, tratar con otro tipo de agrupamiento social, más fácil de describir que basarse en lazos étnicos. Muchos historiadores, desde entonces, habían lamentado su falta de habilidad para tomar, en debida cuenta, los diversos elementos de la población de los Estados Unidos; no fue sino hasta el último cuarto del siglo que se hicieron serios esfuerzos para reconocer la historia de dichos grupos. M.L. Hansen, T.C. Blegen, G.M. Stephenson y el autor del presente trabajo están entre aquellos que han tratado varios aspectos de la inmigración. Pero dichos investigadores han empezado, a duras penas, a revelar las complejidades del problema. De la misma manera unos cuantos artículos y monografías han prestado alguna atención al desarrollo del negro, en la esclavitud y en la libertad, suficiente para enfatizar lo que aún queda por hacer. ${ }^{23}$

En contraste, el volumen de trabajo fructífero en la historia de las ideas, ha sido más impresionante. La nueva historia había estado inclinada a enlazar la historia social con la intelectual y a acentuar la relación entre las ideas y la experiencia. Tal acercamiento fue ilustrativo, ya que proveía un contexto útil para las discusiones que habían sido, hasta ese momento, muy abstractas y ahistóricas. El peligro en el tratamiento era la tentación de hacer el examen de las ideas como puras reflexiones del contexto o como racionalización de intereses.

La obra más ampliamente leída sobre historia intelectual a finales de la década de 1920 y 1930, Main Currents de V. L. Parrington, sucumbió completamente a ese peligro y aceptó, en su forma más simple, la dicotomía de los intereses agrario-capitalistas que entonces habían atraído también a Beard. Pero la influencia de Parrington probó tener vida corta; y tanto él, como Beard, carecieron de discípulos. R. H. Gabriel y Merle Curti, aunque conscientes del fondo social, trataron, no obstante, las ideas que les interesaban como si fueran dignas de atención seria. La generación más joven da muestras de una mayor profundidad en el tratamiento. A. M. Schlesinger Jr., Richard Hofstadter, D. J. Boorstin y Donald Fleming han llegado, en sus primeros trabajos, a un nivel de discusión que ya ha dado buenos frutos y que promete mejores. Mientras tanto, el interés de Perry Miller por la historia de las ideas religiosas rindió los mejores resultados. ${ }^{24}$

Fue la esperanza de los nuevos historiadores no solamente triunfar en abrir áreas nuevas de investigación, sino también poder revi-

22 A.M. Schlesinger, Colonial Merchants and American Revolution, Nueva York, 1918.

${ }^{23}$ M.L. Hansen, Atlantic Migration, Cambridge, Mass.,1940, e Immigrant in American History, Cambridge, Mass., 1941; T.C. Blegen, Norvegian Migration to America, Northfield, Minn., 1931-40; G.M. Stephenson, Religions Aspects of Swedish Immigation, Chicago, 1932; Oscar Handlin, The Uprooted, Boston, 1951.

24 V.L. Parrington, Main Currents in American Thought, Nueva York, 1927-30; R.H. Gabriel, Course of American Democratic Thought, Nueva York, 1940; M.E. Curti, Growth of American Thought, Nueva York, 1943; A.M. Schlesinger Jr., Orestes A. Brownson, Boston, 1939; Richard Hofstadter, Social Darwinism, Filadelfia, 1944; D.J. Boorstin, Lost World of Thomas Jefferson, Nueva York, 1948; Donald Fleming, William H. Welch, Boston, 1954; Perry Miller, New England Mind, Nueva York y Cambridge, 1939, 1953. 
sar los temas tradicionales de la economía, la política y la diplomacia. Han tenido sólo éxito parcial. Los trabajos que muestran un pensamiento sereno son realmente raros. ${ }^{25}$

Por más de una década los intelectuales norteamericanos han formado parte de un movimiento consciente para fortalecer la historia económica. Algunos de los trabajos auspiciados por el Comité para las Investigaciones de Historia Económica (Committee on Research in Economic History), han hecho valiosas contribuciones a la materia, en métodos y temas. Men, Cities and Transportation, estudio sobre la Nueva Inglaterra de E. C. Kirkland, resultó un trabajo de erudición y atractivo que trató los problemas económicos en contraste con un extenso fondo social. Por otro lado, The Economic History of the United States, editada por Henry Davis y otros, produjo un útil sumario de estudios existentes, aunque resultó muy convencional en tratamiento. Las historias de los negocios, cuyo número parece aumentar constantemente, ha creado un impresionante cuerpo de información acerca de numerosas firmas en cada rama de la economía; sin embargo, no han introducido importantes modificaciones en los conceptos existentes sobre las operaciones del sistema productivo. ${ }^{26}$

La historia política nunca ha dejado de interesar a un diligente grupo de historiadores. El volumen de sus trabajos se ha ocupado de las luchas por el control del gobierno, a la manera de los historiadores narradores del siglo XIX, aunque sobre un campo más limitado. No obstante, muchas veces la importancia de las ideas nuevas no se perdió en aquellos que escribieron en este campo. Con frecuencia, nueva luz fue arrojada sobre viejos problemas al tomar en cuenta la posición del oeste, como en Mississippi Valley in British Politics, de Alvord, o al reexamen de los intereses involucrados como en Navigation Acts and the American Revolution de Dickerson, o al análisis parcial como en Whig Party in the South de A. C. Cole. Recientemente se han sacado a relucir interesantes conexiones entre la historia intelectual y política por A. M. Schlesinger Jr. y Richard Hofstadter, al mismo tiempo retratos realistas de personajes centrales de la política por A. S. Link, Frank Friedel, y J. M. Blum, han puntualizado las operaciones del gobierno en los últimos cincuenta años. ${ }^{27}$

Las reglas de la historia diplomática han demostrado ser demasiado rígidas para permitir desviaciones al tratamiento tradicional. Algunos escritores - Bailey, Perkins, Merk, Pratt, Heindel y Leo-

25 Para su exposición véase "American Historical Association, Committee of The Planning of Research", Historical Scholarship in America: Needs and Opportunities, Nueva York, 1932.

${ }^{26}$ E.C. Kirkland, Men, Cities and Transportation, Cambridge, Mass., 1948; H. Davis et al., Economic History of the United States, Nueva York, 1945-51; L.C. Hunter, Steamboats on the Western Rivers, Cambridge, Mass., 1949; Oscar y Mary F. Handlin, Commonwealth, Nueva York, 1947; Louis Hartz, Economic Policy and Democratic Thought, Cambridge, Mass., 1948. Para la historia de los negocios véase H.M. Larson (comp.), Guide to Business History, Cambridge, Mass., 1848.

27 C.W. Alvord, Mississippi Valley in British Politics, Cleveland, 1916; A.C. Cole, Whig Party in the South, Washington, 1913; O.M. Dickerson, Navigation Acts and the American Revolution, Filadelfia, 1951; A.M. Schlesinger Jr., Age of Jackson, Boston, 1945; Richard Hofstadter, American Political Tradition, Nueva York, 1948; A.S. Link, Wilson, Princeton, 1947; Frank Friedel, Franklin D. Roosevelt, Boston, 1952-54; J.M. Blum, Joe Tumulty, Boston, 1951. 
pold, entre otros - han intentado otorgar nueva consideración a la opinión pública, al regionalismo y a los factores culturales y económicos. Monografías ocasionales han demostrado potencialidades en este campo. Pero el volumen de la producción en la historia diplomática y algo de lo mejor de ella -John Quincy Adams, de Bemis, por ejemplo- continúan con el estilo del siglo pasado. ${ }^{28}$

El trabajo en la historia constitucional, donde los historiadores comparten el campo con abogados y politólogos, ha estado menos dispuesto al cambio. Swisher, Corwin, Wright, y otros han contribuido con evaluaciones modernas sobre los hombres y las ideas. Pero los temas no han partido expresamente de los conceptos básicos hace mucho tiempo esbozados por Von Holst, Schouler, y los otros historiadores-narradores. ${ }^{29}$

Por último, se puede decir que a pesar de toda la atención prodigada últimamente, bajo el estímulo de la guerra, la elaboración de la historia militar no ha manifestado vitalidad intelectual. Los más importantes logros - la historia elaborada por el ejército en la Segunda Guerra Mundial, el estudio de la Marina de Morison, Washington y Lee, de Freeman, y Great War for the Empire, de Gibson - han sido notables por su minuciosidad y tamaño. Hubo algo de atención a los problemas de logística, al problema de las decisiones y a la posición del soldado corriente. Pero sería demasiada pretensión decir que dichas discusiones - cuando ocurrenhan sido bien integradas en el relato total o que las narraciones, de por sí, han partido directamente de los métodos de los historiadores militares clásicos. ${ }^{30}$

El objeto de este rápido sumario de lo escrito recientemente debe ser adecuado. No fue suficiente crear una nueva historia únicamente para rellenar campos olvidados o para poner los viejos "al día". La labor más ardua y los esfuerzos más valiosos podrían así, producir sólo una más en la larga lista de útiles, pero estériles monografías, útil en aquel libro que pudiera adicionar un pormenor exacto al conocimiento, si alguien lo consultara, pero estéril porque no dice nada en sí y tendría valor sólo si alguien lo usara.

Se necesitó algo más: la habilidad para establecer preguntas con sentido sobre el material, cualquiera que fuese su naturaleza. Los historiadores cuyos empeños fructificaron más, fueron aquellos capaces de elevar dichas preguntas en cualquier campo. Fueron, a pesar de todo, una pequeña minoría entre los que escribían y enseñaban historia en los Estados Unidos. El hecho de que al escribir la historia norteamericana en general, no se hayan preguntado cues-

28 T.A. Bailey, Theodore Roosevelt and Japanese-American Crisis, Stanford, 1934; y Woodrow Wilson, Nueva York, 1944-45; Dexter Perkins, Monroe Doctrine, Cambridge, Mass., 1923; Frederick Merk, Albert Gallatin and Oregon, Cambridge, Mass., 1950; J.W. Pratt, Expansionists of 1812, Nueva York, 1949; R.H. Heindel, American Impact on Great Britain, Filadelfia, 1940; R.W. Leopold, "Mississippi Valley and Foreign Policy", Mississippi Valley Historical Review, XXXVII (1951), 625; S.F. Bemis, John Quincy Adams, Nueva York, 1949.

29 C.B. Swisher, American Constitutional Development, Boston, 1943; E.S. Corwin, Doctrine of Judicial Review, Princeton, 1914; B.F. Wright, American Interpretation of Natural Law, 1931.

30 United States Army in World War II, Washington, 1947-54; S.E. Morison, History of the United States Naval Operations in World War II, Boston, 1947-54; D.S. Freeman, R.E. Lee, Nueva York, 1934-35; y George Washington, 1948-52; L.H. Gipson, Great War for the Empire, Nueva York, 1953. 
tiones fundamentales, es resultado de factores concretos que los han hecho incapaces de comprender la necesidad de dichas complicaciones.

Los historiadores norteamericanos no fueron afectados en gran medida por el desafío intelectual del marxismo. Esto se debió, en parte, a la debilidad general de los movimientos socialistas en los Estados Unidos y en otra, a la persistencia de las concepciones de la singularidad del Nuevo Mundo. Es más, los historiadores norteamericanos fueron indiferentes a la versión populista de la lucha de clases entre agraristas y capitalistas. A pesar de los cargos engañosos últimamente hechos en Capitalism and the Historians de F. A. Hayek, los intelectuales han aceptado unánimemente la libre empresa; su propio status profesional, su clase media y una constante fe en la misión norteamericana, explican esto. ${ }^{31}$

En general, tampoco prestaron atención a la súplica de los "relativistas", cuya preocupación por la historiografía produjo el llamado para que los escritores actuales abjuraran de la búsqueda de la verdad "absoluta" y dirigieran su investigación a iluminar los problemas contemporáneos. En las décadas de 1920 y 1930, la preocupación por los resultados de la Primera Guerra Mundial, produjo una interpretación "revisionista" de dicho conflicto y de la guerra civil en parte, pero en parte negativa, ya que produjo un sentimiento derrotista extremo. Fuera de esto, las crisis sucesivas de los últimos cuarenta años apenas han sido reflejadas en los escritos históricos.

En fin, los historiadores no han querido armonizar sus investi gaciones con los cambios de intereses en las ciencias sociales. Los cambios radicales en las teorías económicas, sociológicas y psicológicas en las últimas décadas, no han producido las alteraciones de énfasis que corresponderian en el trabajo de los historiadores. Tampoco los esfuerzos conscientes del Consejo de Investigaciones de las Ciencias Sociales (Social Research Council) y otros grupos para enfocar la atención, han tenido resultados importantes. La sumisión respetuosa al tratamiento "interdisciplinario" ha sido rara vez llevada de la mesa de conferencias al escritorio de trabajo.

Estas actitudes son aspectos del carácter profesional en la elaboración de la historia en los Estados Unidos. Desde 1880, por su ingreso, educación, adiestramiento, organización, publicaciones y actuación profesional, los historiadores han hecho un oficio. En los métodos de enseñanza y en sus relaciones con la universidad han logrado superar las esperanzas de aquellos que postularon la historia como ciencia, a la cual había que dedicarse profesionalmente. Esto ha sido la fuente de las fuerzas y la debilidad de la historia norteamericana.

Observada desde un punto de vista real, la profesión no ambiciona producir algunos eruditos auténticos. Su objetivo es suministrar miles de maestros con el sello del doctorado, que los cientos de instituciones superiores y escuelas secundarias demandan. Desde el punto de vista de la erudición creativa, hay algo patético en la tesis doctoral; arduamente compilada, meticulosa en su aparato, veraz en los hechos, resulta árida intelectualmente, y por lo general, significa el fin, más que el principio en la carrera de escritor. Pero

31 Harvard Guide to American History, p. 17. 
desde el punto de vista de su función en la educación norteamericana, no es despreciable aportación que una inmensa proporción de maestros tengan, cuando menos una vez en su vida, que aprender a través de este ejercicio los valores de precisión, de juicio equilibrado y de percepción. Si dichos ejercicios producen además, ocasionalmente, contribuciones al conocimiento, habrán superado su propósito.

Las cualidades del adiestramiento para lograr esos fines no son, a pesar de todo, suficientes para obtener una erudición original. La habilidad para hacer preguntas inteligentes y novedosas, ejercitar un juicio crítico para adquirir conclusiones amplias y descubrir las relaciones entre las experiencias del presente y los datos del pasado, no son desalentadas por las universidades y por la profesión en general, sencillamente y por la naturaleza del caso, están descuidadas. El escritor excepcional que, por una causa u otra, mantiene su creatividad no se encuentra con la oposición de sus colegas y maestros, sino, lo que puede ser más desalentador, con su apatía. Si dichos escritores, con todo, son bastante firmes de espíritu y continúan expresándose, son respetados.

Para estos intelectuales la tradición de la historiografía norteamericana puede ser fructifera. Su tendencia científica la ha dejado libre de manías, tolerante al eclecticismo, flexible en sus métodos y dedicada a la verdad; persiste en reconocer como objetivo el comunicar sus resultados a un extenso público hasta donde sea posible; y el tema de la experiencia en el Nuevo Mundo proporciona al historiador con imaginación, un tema digno de su mayor esfuerzo. 